\title{
PRIORITAS LOKASI REVITALISASI SUNGAI CILIWUNG DI WILAYAH DKI JAKARTA
}

\section{CILIWUNG RIVER REVITALIZATION PRIORITISED LOCATION IN DKI JAKARTA}

\author{
Roby Dwiputra' ${ }^{1,2}$, Eko Kusratmoko ${ }^{3}$, \& Rudy Parluhutan Tambunan ${ }^{4}$ \\ ${ }^{1}$ Dinas Cipta Karya, Tata Ruang dan Pertanahan Provinsi DKI Jakarta \\ ${ }^{2}$ Kajian Pengembangan Perkotaan Sekolah Kajian Stratejik dan Global Universitas Indonesia \\ ${ }^{3}$ Fakultas Matematika dan Ilmu Pengetahuan Alam Univeristas Indonesia \\ ${ }^{4}$ Sekolah Ilmu Lingkungan Universitas Indonesia \\ e-mail : roby.dwiputra@gmail.com
}

Diterima tanggal: 5 Februari 2022 ; diterima setelah perbaikan: 10 Februari 2021 ; Disetujui tanggal: 015 Februari 2021

\begin{abstract}
ABSTRAK
Kondisi geomorfologi Jakarta serta bentuk aliran sungai yang bercorak peneplain dibenturkan dengan terjadinya degradasi lingkungan akibat kepadatan penduduk yang terus bertambah menyebabkan kerentanan Jakarta terhadap ancaman bahaya banjir terus meningkat. Dari ke-13 sungai yang mengalir di Jakarta, Sungai Ciliwung menjadi perhatian utama bermula dari sejarahnya sebagai fungsi vital bagi Jakarta sejak jaman Pemerintahan Belanda yang mana merawat Sungai Ciliwung pada saat itu sama dengan menjaga harkat dan martabat Batavia (sekarang Jakarta). Pembelajaran dari negara-negara di Eropa atau Amerika, konsep penanganan sungai yang berhasil dilaksanakan dan menjadi contoh bagi negara lain yaitu menggunakan pendekatan revitalisasi. Revitalisasi sungai berdampak pada peningkatan kualitas lingkungan dan kehidupan yang juga sekaligus menjadi dasar pembangunan berkelanjutan. Urgensi revitalisasi sungai membuat penelitian ini penting untuk dilakukan, yakni membahas kriteria revitalisasi sungai dari perspektif kajian perkotaan untuk mendapatkan tingkat prioritas lokasi revitalisasi. Penelitian menggunakan pendekatan kuantitatif dengan metode Analisis Hirarki Proses (AHP) dan analisis spasial berbasis Sistem Informasi Geografis (SIG). Hasil penelitian menunjukkan bahwa kriteria faktual banjir merupakan kriteria penentu lokasi dengan bobot tertinggi, yaitu 32,4\% sehingga setiap segmen pelaksanaan revitalisasi harus memiliki dampak yang besar bagi pengendalian banjir di Jakarta. Adapun lokasi revitalisasi sangat prioritas dimulai dari Jalan TB Simatupang sampai Pintu Air Manggarai.
\end{abstract}

Kata kunci: AHP, banjir, prioritas, revitalisasi sungai, spasial.

\section{ABSTRACT}

The geomorphological conditions of Jakarta and the shape of the river flow with a peneplain pattern are collided with environmental degradation due to the increasing population density, causing Jakarta's vulnerability to the threat of flooding continue to increase. Of the 13 rivers that flow in Jakarta, the Ciliwung River has become a major concern starting from its history as a vital function for Jakarta since the days of the Dutch East Indies, when caring for the Ciliwung River at that time was as important as maintaining the dignity of Batavia (n.k.a Jakarta). Learning from countries in Europe or America, the concept of river management that has been successfully implemented and has become an example for other countries are by using a revitalization approach. River revitalization has an impact on improving the quality of the environment and life which is also the basis for sustainable development. The urgency of river revitalization makes this research important to do, namely discussing river revitalization criteria from the perspective of urban studies to get the priority level of revitalization locations. This research uses a quantitative approach with the method of Analytic Hierarchy Process (AHP) and spatial analysis based on Geographic Information Systems (GIS). The results show that flood factual criteria determine the location of river revitalization with the highest score, which is $32.4 \%$ so that each segment of the revitalization implementation must have a major impact on flood protection in Jakarta. The location for the revitalization is very priority starting from TB Simatupang street to the Manggarai Water Gate.

Keywords: AHP, flood, priority, river revitalization, spatial.

Prioritas Lokasi Revitalisasi Sungai Ciliwung di Wilayah DKI Jakarta - Roby Dwiputra, Eko Kusratmoko, \& Rudy 


\section{PENDAHULUAN}

Kondisi fisik Jakarta secara geomorfologi merupakan dataran rendah dengan sungai-sungai yang mengalir di Jakarta bercorak peneplain, dataran yang hampir rata, menyebabkan air permukaan yang tertampung pada sungai mengalir datar seolah gaya gravitasi hampir tidak terpenuhi sehingga bentuk sungai di Jakarta tampak berkelok-kelok. Selain itu, menurut Bemmelen (1949) bahwa kondisi geografis Jakarta menunjukkan terdapat sekitar $40 \%$ wilayah dataran Jakarta terletak di bawah permukaan laut (submerged land), tidak hanya itu dataran yang kondisi geografisnya rendah ini juga dialiri tiga belas sungai yang bermuara di Pantai Utara Jakarta. Jakarta sebagai ibukota Negara memiliki fungsi strategis yang berperan sebagai pusat pemerintahan sekaligus pusat perekonomian memiliki kepadatan penduduk tertinggi di Indonesia dan terus meningkat. Kondisi geografis Jakarta dan tingginya tekanan pada lingkungan di Jakarta menyebabkan kerentanan Jakarta terhadap ancaman banjir terus meningkat yang berpotensi menghasilkan risiko dampak kerugian yang tinggi.

Banjir beserta pengendaliannya sudah ada sejak Abad ke-5 Masehi (Siswadhi, 1982). Pada Prasasti Tugu di Museum Sejarah Jakarta disebutkan pada masa Kerajaan Tarumanegara, Raja Purnawarman pernah melakukan penggalian Kali Gomati (saat ini adalah Kali Mati di Tangerang) dan Kali Chandrabagha (saat ini di Bekasi) untuk mengendalikan permasalahan banjir. Sementara Shahab (2009) dalam bukunya "Batavia kota Banjir" menuliskan banjir terbesar yang pernah terjadi di Jakarta (d/h. Batavia) adalah pada Tahun 1872 yang membuat jebol sluisburg atau pintu air di depan Masjid Istiqlal. Hingga saat ini, pengendalian banjir merupakan salah satu prioritas penting Pemerintah. Pendekatan yang dilakukan Pemerintah Provinsi DKI Jakarta saat ini terfokus pada 6 (enam) aspek, yaitu pembangunan kanal banjir, pemeliharaan sungai, normalisasi sungai, pembuatan tanggul pantai, penataan saluran, serta pembangunan pintu air, rumah pompa dan saringan sampah.

Sementara pada negara-negara di Eropa atau Amerika, konsep penanganan sungai yang telah berhasil dan menjadi contoh bagi negara lain adalah dengan pendekatan revitalisasi. Pada daerah padat penduduk dan area industri seperti Jakarta, revitalisasi sungai memberikan kontribusi yang tinggi pada peningkatan kualitas lingkungan dan juga kehidupan. Badan sungai seringkali menjadi satu-satunya yang berfungsi menjadi wadah bagi keanekaragaman hayati dan menjadi ruang terbuka di perkotaan. Dengan demikian, perlindungan dan pemulihan pada setiap segmen sungai akan menjadi dasar untuk membentuk tatanan ruang kota dan pembangunan yang berkelanjutan (Alokhina, 2020). Manfaat revitalisasi sungai perkotaan dapat dideskripsikan melalui pendekatan 'Jasa Ekosistem' yang merupakan manfaat yang diperoleh masyarakat dari ekosistem (Hassan et al, 2005). Lebih luas definisi Jasa ekosistem adalah aspek ekosistem yang dapat dimanfaatkan secara aktif maupun pasif untuk meningkatkan kesejahteraan manusia (Fisher \& Tunner, 2008).

Dari 13 sungai yang mengalir di Jakarta, sungai yang menjadi perhatian utama antara lain adalah Sungai Ciliwung. Hal ini dimulai dari sejarah panjang Sungai Ciliwung yang pernah berperan sebagai fungsi vital bagi Jakarta seperti yang dikatakan oleh sejarawan Bogor Saleh Danasasmita (1933-1986) bahwa terkait pengelolaan Sungai Ciliwung telah ada sejak jaman Pemerintahan Belanda berkuasa, bahkan bagi Belanda saat itu merawat Sungai Ciliwung sama dengan menjaga harkat dan martabat ibukota, yaitu Batavia, yang sekarang adalah Jakarta. Sementara pada saat ini, yang mana Ciliwung sering kali disebutkan dan dikaitkan sebagai penyebab banjir di Jakarta setiap kali datang musim penghujan dan terjadi banjir.

Urgensi revitalisasi Sungai Ciliwung di Jakarta dan bahaya banjir yang mengancam menyebabkan penelitian ini penting untuk dilakukan yakni membahas dari perspektif kajian pengembangan perkotaan terhadap kerangka desain instrumen revitalisasi yang telah dibuat oleh Pemerintah Provinsi DKI Jakarta untuk mendapatkan tingkat prioritas lokasi revitalisasi Sungai Ciliwung mulai dari perbatasan Depok-Jakarta sampai dengan Pantai Utara Jakarta. Secara umum, tujuan dari penelitian ini adalah membahas kerangka desain instrumen revitalisasi sungai dari perspektif kajian pengembangan perkotaan untuk mendapatkan tingkat skala prioritas lokasi revitalisasi Sungai Ciliwung sebagai upaya pengendalian banjir di Jakarta. Tujuan ini dapat diturunkan pada tujuan khusus yaitu menentukan bobot kriteria penentu lokasi prioritas program revitalisasi sungai yang ideal serta menganalisis, memetakan dan mengklasifikasi lokasi prioritas revitalisasi Sungai Ciliwung di Wilayah DKI Jakarta.

\section{BAHAN DAN METODE}

\section{Waktu dan Lokasi}

Daerah penelitian yang merupakan objek pada 
penelitian ini adalah Sungai Ciliwung dengan area sungai yang berada pada wilayah administrasi Provinsi DKI Jakarta mulai dari perbatasan Depok sampai dengan Pantai Utara Jakarta yang kemudian area penelitian terletak pada sepanjang Sungai Ciliwung dan sempadannya yang merupakah hasil buffer sepanjang Sungai Ciliwung ke kanan dan kiri sejauh 15 m (lima belas meter) dari tepi palung sungai. Penelitian ini dilakukan pada Februari - Agustus 2021. Peta daerah penelitian dapat dilihat pada Gambar 1.

\section{Bahan dan Alat}

Bahan yang digunakan dalam penelitian ini adalah data dan informasi yang didapat berdasarkan kriteria yang ditentukan. Kriteria yang digunakan dalam penelitian mengacu pada berbagai peraturan perundangan di Jakarta sebagaimana dapat dilihat dalam Tabel 1. Sumber data dalam penelitian ini terdiri dari atas sumber data primer serta sumber data sekunder. Adapun sumber data primer didapatkan dari wawancara dan pengisian kuesioner kepada responden sebagai narasumber. Sumber data sekunder berupa studi literatur, interpretasi peta serta foto udara.

Penentuan narasumber dalam penelitian menggunakan pendekatan Purposive, yang ditentukan secara sengaja berdasarkan tingkat kepentingan, pengetahuan dan pengalamannya terhadap permasalahan penelitian (Babbie, 2012). Narasumber terbagi menjadi 3 (tiga) kelompok, yakni: (1) Pemerintah [P] selaku kelompok pemangku kebijakan dan pelaksana penanganan sungai, terdiri atas Pemerintah Pusat yang diwakili oleh Balai Besar Wilayah Sungai Ciliwung-Cisadane [P1] serta Pemerintah Daerah yang diwakili oleh Dinas Sumber Daya Air Provinsi DKI Jakarta [P2] dan Dinas Cipta Karya, Tata Ruang dan Pertanahan Provinsi DKI Jakarta [P3]; (2) Akademisi [A] selaku kelompok para pakar atau ahli di bidangnya, terdiri atas pakar sipil pengairan dari Fakultas Teknik Universitas Indonesia [A1], pakar perencanaan kota dari Sekolah Arsitektur Perencanaan dan Pengembangan Kebijakan Institut Teknologi Bandung [A2], serta pakar informasi geografis dari Fakultas Ilmu dan Teknologi Kebumian Institut Teknologi Bandung [A3]; dan (3) Masyarakat [M] selaku kelompok di luar pemangku kebijakan maupun dan juga di luar akademisi, yaitu kelompok dari ikatan alumni Fakultas Teknik Universitas Indonesia [M1], organisasi profesi bidang perencanaan wilayah dan kota -Ikatan Ahli Perencana (IAP) Daerah Khusus Ibukota Jakarta [M2], dan komunitas masyarakat "Ciliwung Institute" [M3].

Peta yang digunakan merupakan peta dalam koordinat UTM (Universal Transverse Mercator) Zona 48S dan menggunakan Datum WGS 1984 sesuai dengan standar peta yang ditentukan oleh Badan Informasi Geospasial. Adapun peralatan yang digunakan untuk analisis meliputi Laptop, perangkat lunak Expert Choice 11 dan ArcMap 10.4. Hasil pengolahan data ditampilkan dalam bentuk tabel dan peta.

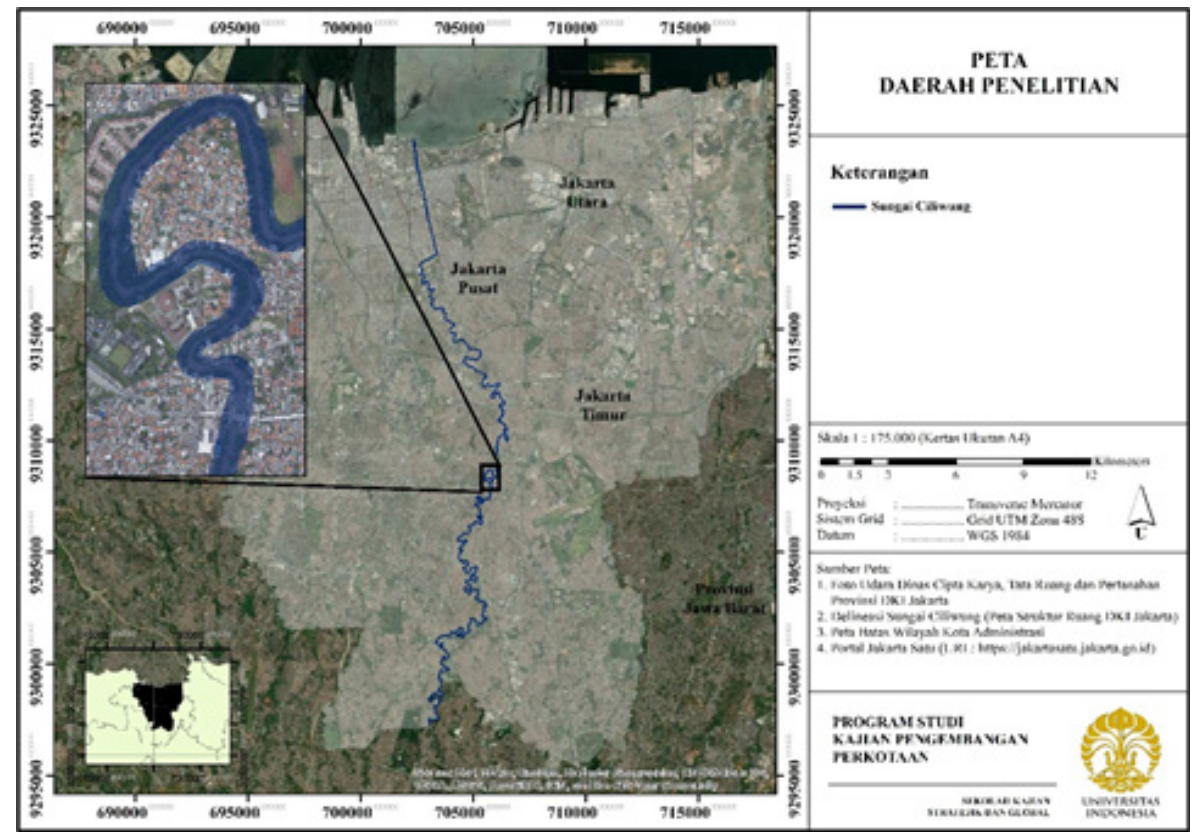

Gambar 1. Peta daerah penelitian

Figure 1. Research area map

Sumber: Olah data Jakarta satu 
Tabel 1. Kriteria dan kebutuhan data

Table 1. Criteria and data requirements

\begin{tabular}{|c|c|c|c|c|}
\hline No & Kriteria & Data & Dasar & Sumber Data \\
\hline 1. & Faktual Banjir & $\begin{array}{l}\text { Peta lokasi sebaran RW } \\
\text { terdampak banjir pada } \\
\text { Januari s.d Juli } 2020\end{array}$ & $\begin{array}{l}\text { Peraturan Gubernur DKI } \\
\text { Jakarta Nomor } 31 \\
\text { Tahun } 2019\end{array}$ & $\begin{array}{l}\text { Badan Penanggulangan } \\
\text { Bencana Daerah } \\
\text { Provinsi DKI Jakarta }\end{array}$ \\
\hline 2. & $\begin{array}{l}\text { Simpangan } \\
\text { Penggunaan } \\
\text { Lahan }\end{array}$ & $\begin{array}{l}\text { Peta simpangan antara } \\
\text { kegiatan pemanfaatan ruang } \\
\text { eksisting dan rencana kota }\end{array}$ & $\begin{array}{l}\text { Peraturan Daerah } \\
\text { Provinsi DKI Jakarta } \\
\text { Nomor } 1 \text { Tahun } 2014\end{array}$ & $\begin{array}{l}\text { Dinas Cipta Karya, Tata Ruang } \\
\text { dan Pertanahan Provinsi } \\
\text { DKI Jakarta }\end{array}$ \\
\hline 3. & Rencana Kota & $\begin{array}{l}\text { Peta informasi rencana kota } \\
\text { skala 1:1000 yang merupakan } \\
\text { turunan dari peta RDTR }\end{array}$ & $\begin{array}{l}\text { Peraturan Daerah Provinsi } \\
\text { DKI Jakarta Nomor } 1 \\
\text { Tahun } 2014\end{array}$ & $\begin{array}{l}\text { i Dinas Cipta Karya, Tata Ruang } \\
\text { dan Pertanahan Provinsi DKI } \\
\text { Jakarta }\end{array}$ \\
\hline 4. & $\begin{array}{l}\text { Kepemilikan } \\
\text { Lahan }\end{array}$ & $\begin{array}{l}\text { Peta status persil tanah berupa } \\
\text { tipe kepemilikan hak atas tanah }\end{array}$ & $\begin{array}{l}\text { Peraturan Gubernur DKI } \\
\text { Jakarta Nomor } 31 \text { Tahun } \\
2019\end{array}$ & $\begin{array}{l}\text { Kantor Wilayah Badan } \\
\text { Pertanahan Nasonal Provinsi } \\
\text { DKI Jakarta }\end{array}$ \\
\hline 5. & Cagar Budaya & $\begin{array}{l}\text { Peta lokasi benda/bangunan cagar } \\
\text { budaya yang telah ditetapkan }\end{array}$ & $\begin{array}{l}\text { Peraturan Daerah } \\
\text { Provinsi DKI Jakarta } \\
\text { Nomor } 9 \text { Tahun } 1999\end{array}$ & $\begin{array}{l}\text { Dinas Kebudayaan Provinsi } \\
\text { DKI Jakarta }\end{array}$ \\
\hline 6. & $\begin{array}{l}\text { Kewajiban } \\
\text { Pihak ke-3 }\end{array}$ & $\begin{array}{l}\text { Peta kewajiban yang ditetapkan } \\
\text { oleh Gubernur kepada pihak ke-3 } \\
\text { Provinsi DKI Jakarta }\end{array}$ & $\begin{array}{l}\text { Peraturan Daerah Provinsi } \\
\text { DKI Jakarta Nomor } 7 \\
\text { Tahun } 2012\end{array}$ & $\begin{array}{l}\text { i Dinas Cipta Karya, Tata Ruang } \\
\text { dan Pertanahan }\end{array}$ \\
\hline 7. & RW Kumuh & Peta klasifikasi RW kumuh & $\begin{array}{l}\text { Peraturan Gubernur DKI } \\
\text { Jakarta Nomor } 90 \text { Tahun } \\
2018\end{array}$ & $\begin{array}{l}\text { Dinas Cipta Karya, Tata Ruang } \\
\text { dan Pertanahan Provinsi DKI } \\
\text { Jakarta }\end{array}$ \\
\hline
\end{tabular}

Sumber: Olahan data pribadi

\section{Metode Penelitian}

Penelitian dilakukan dengan menggunakan pendekatan penelitian kuantitatif. Menurut Emzir (2009), pendekatan kuantitatif ialah pendekatan secara primer denganmenggunakan paradigma postpositivisme dalam pengembangan ilmu pengetahuan, serta menggunakan suatu strategi penelitian seperti survei dan eksperimen yang membutuhkan data statistik. Penelitian dengan pendekatan kuantitatif sebagian besar menggunakan angka, dari pengumpulan data, interpretasi terhadap data tersebut, hingga hasilnya (Arikunto, 2006). Pada penelitian ini, pendekatan campuran yang digunakan adalah deskriptif kuantitatif menggunakan analisis AHP yang dilakukan dengan mengkuantitatifkan data kualitatif kemudian dilanjutkan dengan analisis spasial berbasis SIG dengan metode SMCE (Spatial MultiCriteria Evaluation).

Penelitian dimulai dengan melakukan studi literatur terlebih dahulu. Kemudian ditentukan faktor-faktor atau kriteria penting yang menjadi penentu dalam pemilihan lokasi prioritas revitalisasi sungai yang ideal. Data dan informasi yang sudang dikumpulkan kemudian diolah dan dilakukan analisis dengan 2 (dua) tahapan metode. Tahap pertama merupakan penetapan bobot kriteria yang dilakukan dengan menggunakan metode analisis AHP. Proses hirarki analitik merupakan sesuatu model yang fleksibel yang memungkinkan digunakan untuk mengambil keputusan dengan melakukan kombinasi dari pertimbangan dan nilai pribadi yang dilakukan secara logis. Analisis hirarki proses digunakan pada keputusan untuk banyak kriteria, alokasi sumberdaya, perencanaan dan penentuan prioritas dari strategistrategi yang dimiliki para pemangku kepentingan (Saaty, 2001). Dalam penelitian ini, masing-masing kriteria akan diberikan penilaian menggunakan skala banding secara berpasangan yang diolah dengan perangkat lunak Expert Choice 11 untuk mendapatkan nilai bobot dari masing-masing kriteria. Kemudian dilakukan penilaian gabungan dengan participant yang terdiri atas seluruh responden. Nilai bobot dari masingmasing kriteria yang didapatkan dari hasil penilaian gabungan ini yang akan digunakan pada metode selanjutnya untuk memetakan lokasi prioritas.

Tahap berikutnya yaitu pemetaan lokasi prioritas yang dilakukan menggunakan metode analisis spasial berbasis Sistem Informasi Geografis (SIG) yang diolah dengan perangkat lunak ArcMap 10.4. Sumber data spasial berupa peta diperoleh dari data hasil pengukuran lapangan yang dihasilkan berdasarkan teknik perhitungan tersendiri oleh instansi yang mengeluarkan peta tersebut. Peta yang digunakan sebagian besar merupakan peta tematik yang terdapat 
pada Jakarta Satu, portal milik Pemerintah Provinsi DKI Jakarta yang mengusung konsep satu data, satu peta, satu kebijakan. Termasuk peta yang berasal dari lembaga lain di luar Pemerintah Provinsi DKI Jakarta seperti peta kepemilikan lahan yang bersumber dari Badan Pertanahan Nasional pun telah terintegrasi dengan Jakarta Satu. Metode analisis spasial yang digunakan adalah metode SMCE yang merupakan suatu metode dalam proses pengambilan keputusan dalam perencanaan wilayah dengan menggunakan beberapa kriteria yang berfungsi untuk membantu dalam pengambilan keputusan dalam memilih berbagai alternatif berdasarkan skala prioritas. Kriteria terdiri atas beberapa klasifikasi yang kemudian diberikan nilai skor pada setiap klasifikasi. Skor yang diberikan pada tiap klasifikasi ditentukan berdasarkan pembagian statistik. Dalam penelitian ini, Overlay dilakukan terhadap kriteria-kriteria untuk menentukan hasil akhir setelah diberikan bobot berdasarkan hasil AHP. Kemudian nilai yang telah digabungkan akan diklasifikasian menggunakan natural breaks untuk mendapatkan tingkat prioritas.

\section{HASIL DAN PEMBAHASAN}

Ruang sungai sebagai sistem drainase air permukaan yang meliputi badan sungai dan area sempadan (Budd et al., 1987). Sempadan sungai digambarkan sebagai area yang mana terjadi interaksi biologis, fisik dan kimia antara ekosistem air dan ekosistem tanah. Interaksi antara tanah dan air menciptakan habitat tanaman dan hewan yang beragam dan produktif. Ketersediaan air, kelembapan tanah, dan keberagaman tanaman membuat area tersebut menarik bagi manusia, hewan ternak, dan makhluk hidup lainnya (Bolton \& Shellberg, 2001). Dengan demikian, sempadan sungai membentuk zona interaksi langsung 3 (tiga) dimensi yang meluas ke luar hingga batas banjir, ke atas hingga vegetasi tepi sungai, dan turun ke bawah menuju sistem air tanah. Sempadan sungai berfungsi sebagai ruang penyangga antara ekosistem daratan dan sungai yang berfungsi agar sungai dengan kegiatan manusia tidak saling terganggu. Sempadan sungai meliputi ruang di kanan dan kiri palung sungai di antara tepi luar kaki tanggul dan garis sempadan untuk sungai bertanggul, atau di antara tepi palung sungai dan garis sempadan untuk sungai tidak bertanggul. Ukuran area sempadan dan interaksi antara tanah dan air bervariasi tergantung ukuran lebar sungai (Bilby \& Bisson, 1998). Berapapun ukuran sungai, area sempadan sangat penting untuk menjaga kesehatan ekologis sungai tersebut. Kuantitas dan kualitas air sungai mencerminkan kondisi pada hulu sungai termasuk area sempadan dan dataran sekitarnya (Bolton \& Shellberg, 2001).

Di Indonesia, garis sempadan pada sungai ditetapkan berdasarkan Peraturan Pemerintah Nomor 38 Tahun 2011 tentang Sungai yang kemudian diturunkan pada Peraturan Menteri Pekerjaan Umum dan Perumahan Rakyat Nomor 28/PRT/M/2015 tentang Penetapan Garis Sempadan Sungai dan Garis Sempadan Danau, bahwa garis sempadan sungai yang berada di dalam kawasan perkotaan dibedakan untuk penetapannya antara sungai tidak bertanggul dan bertanggul. Untuk sungai yang tidak bertanggul, ditentukan garis sempadan sungai berdasarkan kedalaman sungai; (1) Kedalaman sungai yang kurang dari atau sama dengan 3 meter ditentukan garis sempadan sungai sekurangkurangnya berjarak 10 meter dari tepi kanan dan kiri palung sungai; (2) Kedalaman sungai yang lebih dari 3 meter sampai dengan 20 meter sekurang-kurangnya berjarak 15 meter; dan (3) Kedalaman sungai yang lebih dari 20 meter sekurang-kurangnya berjarak 30 meter. Sementara untuk sungai bertanggul, ditentukan garis sempadan sungai sekurang-kurangnya berjarak 3 meter dari tepi luar tanggul.

Dibandingkan sungai-sungai di area lain, sungai perkotaan telah banyak tercemar aktivitas manusia. Pemulihan sungai secara menyeluruh merupakan hal yang tidak mungkin, sehingga perencanaan restorasi sungai perkotaan harus mempertimbangkan ekologi sungai, teknologi yang digunakan, kondisi sosialekonomi, dan lain sebagainya. Dikarenakan sungai perkotaan merupakan penunjang utama pada sistem perkotaan, dalam perencanaannya perlu diberikan perhatian lebih untuk mengantisipasi karakter manusia yang berkembang dan memerhatikan hal yang tidak diinginkan manusia sehingga terbentuk ekosistem yang sehat berbeda dari ekosistem terdahulu dan menyediakan sistem sosial-ekonomi yang lebih baik untuk perkotaan (Zhao et al., 2007). Konsep sungai perkotaan menggabungkan antara rancangan yang berorientasi alami dan gaya hidup perkotaan.

Penentuan bobot kriteria untuk menentukan lokasi revitalisasi sungai dilakukan dengan menggunakan metode AHP guna mendapatkan bobot dari masingmasing kriteria. Setiap kriteria atau faktor dalam menentukan lokasi revitalisasi sungai diberikan penilaian dengan menggunakan skala banding secara berpasangan. Penentuan bobot dari setiap kriteria dalam penentuan lokasi revitalisasi sungai dibantu oleh perangkat lunak Expert Choice 11 dengan melakukan input data jawaban dari responden yang dianggap expert untuk menentukan bobot tersebut dengan 
Tabel 2. Hasil penilaian bobot kriteria

Table 2. The result of the criteria assessment

\begin{tabular}{|c|c|c|c|c|c|c|c|c|c|c|c|}
\hline \multirow[t]{2}{*}{ No } & \multirow[t]{2}{*}{ Kriteria } & \multicolumn{3}{|c|}{ Pemerintah (\%) } & \multicolumn{3}{|c|}{ Akademisi (\%) } & \multicolumn{3}{|c|}{ Masyarakat (\%) } & \multirow[t]{2}{*}{ Gabungan } \\
\hline & & P1 & $\mathbf{P 2}$ & $\mathbf{P 3}$ & $\overline{A 1}$ & A2 & A3 & M1 & M2 & M3 & \\
\hline 1. & Faktual Banjir & 34,9 & 47,6 & 52,8 & 12,3 & 14,4 & 37,8 & 28,4 & 29,0 & 15,1 & $32,4 \%$ \\
\hline 2. & Guna Lahan & 14,8 & 19,7 & 8,3 & 29,3 & 13,1 & 9,7 & 8,3 & 28,9 & 4,4 & $22,6 \%$ \\
\hline 3. & Rencana Kota & 14,5 & 4,0 & 10,9 & 2,8 & 45,6 & 26,7 & 21,0 & 16,8 & 5,0 & $14,2 \%$ \\
\hline 4. & Cagar Budaya & 22,3 & 5,3 & 7,0 & 21,1 & 13,4 & 3,0 & 2,0 & 2,9 & 45,6 & $09,9 \%$ \\
\hline 5. & Kepemilikan & 2,8 & 9,5 & 2,5 & 23,5 & 7,7 & 3,4 & 13,2 & 16,0 & 10,0 & $07,4 \%$ \\
\hline 6. & RW Kumuh & 2,7 & 10,3 & 10,3 & 6,9 & 3,0 & 2,9 & 24,9 & 2,9 & 16,3 & $07,0 \%$ \\
\hline 7. & Pihak ke-3 & 8,0 & 3,6 & 8,3 & 4,0 & 2,8 & 16,4 & 2,2 & 3,4 & 3,6 & $06,7 \%$ \\
\hline
\end{tabular}

pertimbangan masing-masing responden yang terdiri atas perwakilan dari Pemerintah [P], Akademisi [A] dan Masyarakat $[\mathrm{M}]$ sebagaimana dapat dilihat dalam Tabel 2.

Prioritas lokasi revitalisasi sungai didapatkan setelah dilakukan analisis overlay data spasial menggunakan SIG (Sistem Informasi Geografis) dengan metode SMCE (Spatial Multi-Criteria Evaluation) dengan menggunakan bobot kriteria sesuai hasil AHP. Kriteria kemudian diberikan bobot sesuai dengan hasil analisis penilaian yang dilakukan dengan bantuan Expert Choice 11 setelah mendapatkan pertimbangan dari penlaian para expert untuk menentukan nilai dari kriteria yang akan menentukan prioritas lokasi revitalisasi Sungai Ciliwung sebagaimana dapat dilihat pada Tabel 3.

Setelah menggabungkan layer seluruh kriteria yang telah diberikan penilaian melalui proses overlay dengan teknik Geoprocessing -> Union menggunakan Software ArcMap maka didapat 1 (satu) layer Shapefile (.shp) yang berisikan keseluruhan kriteria termasuk dengan data dan informasi yang tersimpan dalam data attribute table.

Tabel 3. Penetapan bobot dan skor untuk setiap kriteria

Table 3. Determination of criteria value

\begin{tabular}{lllll}
\hline No & Faktual Banjir & Skor & Bobot & Nilai \\
\hline 1. & $10-30 \mathrm{~cm}$ & 0,25 & 0,324 & 0,081 \\
2. & $31-70 \mathrm{~cm}$ & 0,50 & 0,324 & 0,162 \\
3. & $71-150 \mathrm{~cm}$ & 0,75 & 0,324 & 0,243 \\
4. & $>150 \mathrm{~cm}$ & 1,00 & 0,324 & 0,324 \\
\hline No & Kepemilikan & Skor & Bobot & Nilai \\
\hline 1. & Hak Milik & 0,0 & 0,074 & 0,0000 \\
2. & HGB & 0,2 & 0,074 & 0,0148 \\
3. & Hak Pakai & 0,4 & 0,074 & 0,0296 \\
4. & HPL & 0,6 & 0,074 & 0,0444 \\
5. & Hak Lain & 0,8 & 0,074 & 0,0592 \\
6. & Tidak Ada & 1,0 & 0,074 & 0,0740 \\
\hline No & Pihak ke-3 & Skor & Bobot & Nilai \\
\hline 1. & Ada Kewajiban & 0 & 0,067 & 0,000 \\
2. & Tidak Ada & 1 & 0,067 & 0,067 \\
\hline
\end{tabular}

\begin{tabular}{lllll}
\hline No & Guna Lahan & Skor & Bobot & Nilai \\
\hline 1. & Tidak Sesuai & 0,5 & 0,226 & 0,081 \\
2. & Sesuai & 1,0 & 0,162 & 0,162 \\
\hline No & Rencana Kota & Skor & Bobot & Nilai \\
\hline 1. & Zona ex-Hijau & 0 & 0,142 & 0,000 \\
& dan Biru & & & \\
2. & Zona Hijau \& & 1 & 0,142 & 0,142 \\
& Biru & & & \\
\hline No & Cagar Budaya & Skor & Bobot & Nilai \\
\hline 1. & Terdapat 0 & 0,099 & 0,000 & \\
2. & Tidak Terdapat & 1 & 0,099 & 0,099 \\
\hline No & RW Kumuh & Skor & Bobot & Nilai \\
\hline 1. & Sangat Ringan & 0,25 & 0,070 & 0,0175 \\
2. & Ringan & 0,50 & 0,070 & 0,0350 \\
3. & Sedang & 0,75 & 0,070 & 0,0525 \\
4. & Berat & 1,00 & 0,070 & 0,0700 \\
\hline & & & & \\
\hline
\end{tabular}

Sumber: Hasil analisis data, 2021 
Tabel 4. Penilaian keseluruhan kriteria dan klasifikasi potensi

Table 4. Overall assessment of criteria and potential classificarion

\begin{tabular}{lll}
\hline No & Nilai keseluruhan & Keterangan klasifikasi \\
\hline 1. & $<0,4550$ & Berpotensi Rendah Menjadi Lokasi Prioritas Revitalisasi \\
2. & 0,4550 s.d 0,5900 & Berpotensi Sedang Menjadi Lokasi Prioritas Revitalisasi \\
3. & 0,5900 s.d 0,7432 & Berpotensi Tinggi Menjadi Lokasi Prioritas Revitalisasi \\
4. & $>0,7432$ & Berpotensi Sangat Timggi Menjadi Lokasi Prioritas Revitalisasi \\
\hline \multicolumn{2}{l}{ Sumber: Hasil analisis data, 2021 }
\end{tabular}

Keseluruhan nilai kriteria yang tersimpan dalam data attribute table kemudian dijumlahkan dan setelahnya dibagi menjadi 4 (empat) klasifikasi berdasarkan pembagian menggunakan natural breaks. Hasil dari klasifikasi tersebut diberikan keterangan berdasarkan tingkat potensi untuk menjadi prioritas lokasi revitalisasi sebagaimana dapat dilihat pada Tabel 4. Hasil pemetaan mengacu pada penilaian klasifikasi lokasi prioritas. Area-area berpotensi dikelompokkan berdasarkan jarak antara satu area dan area lainnya dengan memerhatikan lokasi dan segmen pada Sungai Ciliwung sehingga didapatkan lokasi-lokasi segmen Sungai Ciliwung berdasarkan skala prioritasnya untuk dilaksanakan kegiatan revitalisasi. Adapun skala prioritas tersebut dibagi ke dalam 4 (empat) tingkat prioritas yaitu sangat prioritas, cukup prioritas, kurang prioritas dan tidak prioritas.

Area Sungai Ciliwung berikut sempadannya pada segmen Jalan TB Simatupang s.d Pintu Air Manggarai didominasi oleh area yang berpotensi sangat tinggi untuk dilaksanakan revitalisasi sungai.
Meskipun terdapat sebagain area yang juga terdiri atas area berpotensi sedang dan tinggi, namun dengan mendominasinya area berpotensi sangat tinggi maka Sungai Ciliwung Segmen Jalan TB Simatupang s.d Pintu Air Manggarai sebagaimana dapat dilihat pada Gambar 2 dengan panjang + 23.993 m (lebih kurang dua puluh tiga ribu Sembilan ratus Sembilan puluh Sembilan tiga meter) dijadikan lokasi revitalisasi sangat prioritas. Lokasi revitalisasi Sungai Ciliwung cukup prioritas terletak pada 2 (dua) segmen, yaitu Sungai Ciliwung pada segmen Lenteng Agung s.d Lapangan Tembak Kopassus dan Sungai Ciliwung pada segmen Masjid Istiqlal s.d Pantai Utara Jakarta.

Area Sungai Ciliwung berikut sempadannya pada segmen Lenteng Agung s.d Lapangan Tembak Kopassus dan pada segmen Masjid Istiqlal s.d Pantai Utara Jakarta didominasi oleh area berpotensi tinggi dan sedang, kemudian terdapat beberapa area yang tidak terlalu luas berpotensi rendah, dan tidak terdapat area berpotensi sangat tinggi. Hal ini menyebabkan Sungai Ciliwung Segmen Lenteng Agung s.d Lapangan

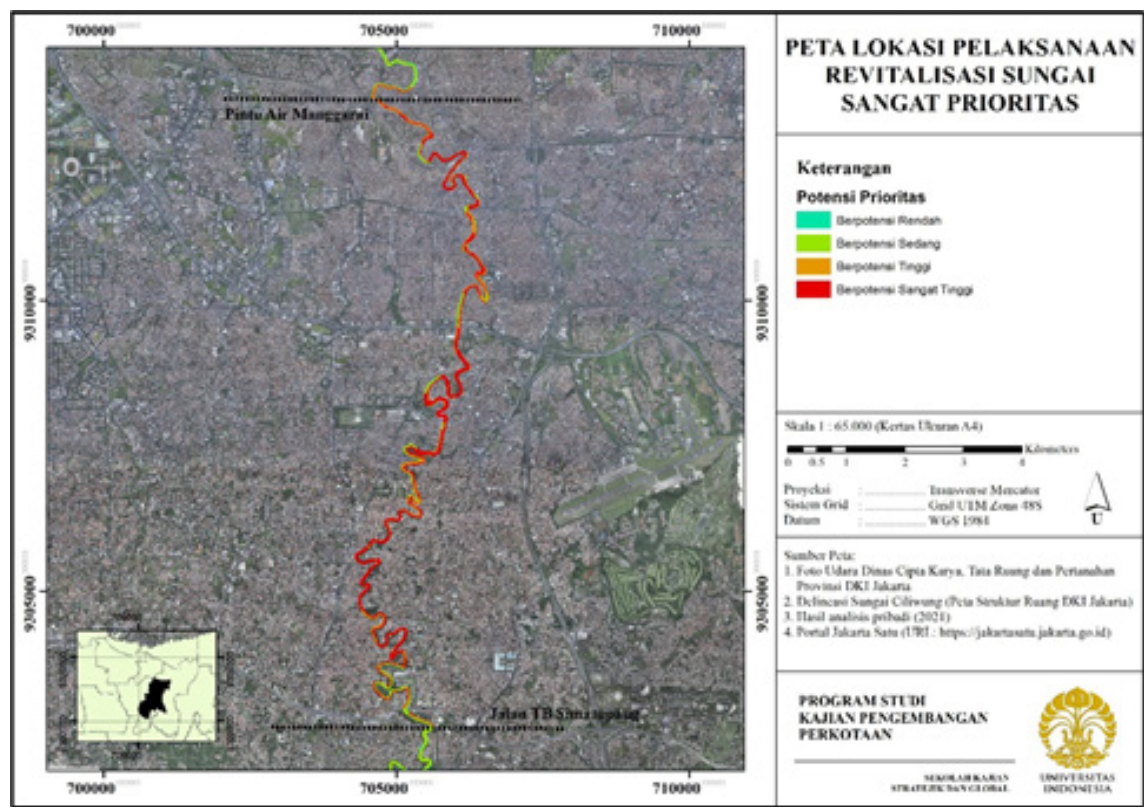

Gambar 2. Peta lokasi revitalisasi sungai ciliwung sangat prioritas.

Figure 2. The map of the ciliwung river revitalization very prioritized location. Sumber: Hasil analisis data, 2021 
Tembak Kopassus sebagaimana dapat dilihat pada Gambar 3 dengan panjang $+3.984 \mathrm{~m}$ (lebih kurang tiga ribu Sembilan ratus delapan puluh empat meter) dan segmen Masjid Istiqlal s.d Pantai Utara Jakarta sebagaimana dapat dilihat pada Gambar 4 dengan panjang $+6.635 \mathrm{~m}$ (lebih kurang enam ribu enam ratus tiga puluh lima meter) menjadi lokasi revitalisasi cukup prioritas.

Lokasi revitalisasi Sungai Ciliwung kurang prioritas terletak pada 2 (dua) segmen, yaitu Sungai Ciliwung pada segmen Lapangan Tembak Kopassus s.d Jalan TB Simatupang dan Sungai Ciliwung pada segmen Pintu Air Manggarai s.d Masjid Istiqlal. Area Sungai Ciliwung

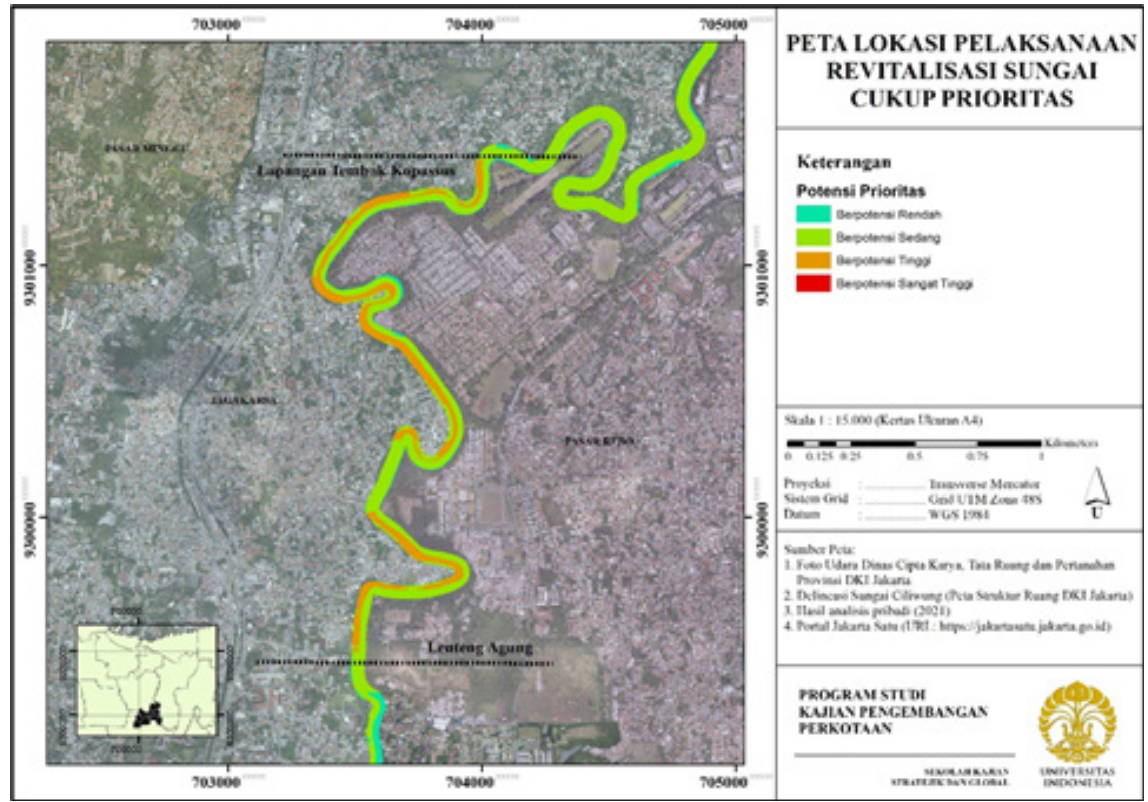

Gambar 3. Peta lokasi revitalisasi sungai ciliwung cukup prioritas:lenteng agung s.d lapangan tembak Kopassus.

.Figure 3. The map of the ciliwung river revitalization enough prioritized location:from Lenteng Agung to the kopassus shoot field.

Sumber: Hasil analisis data, 2021

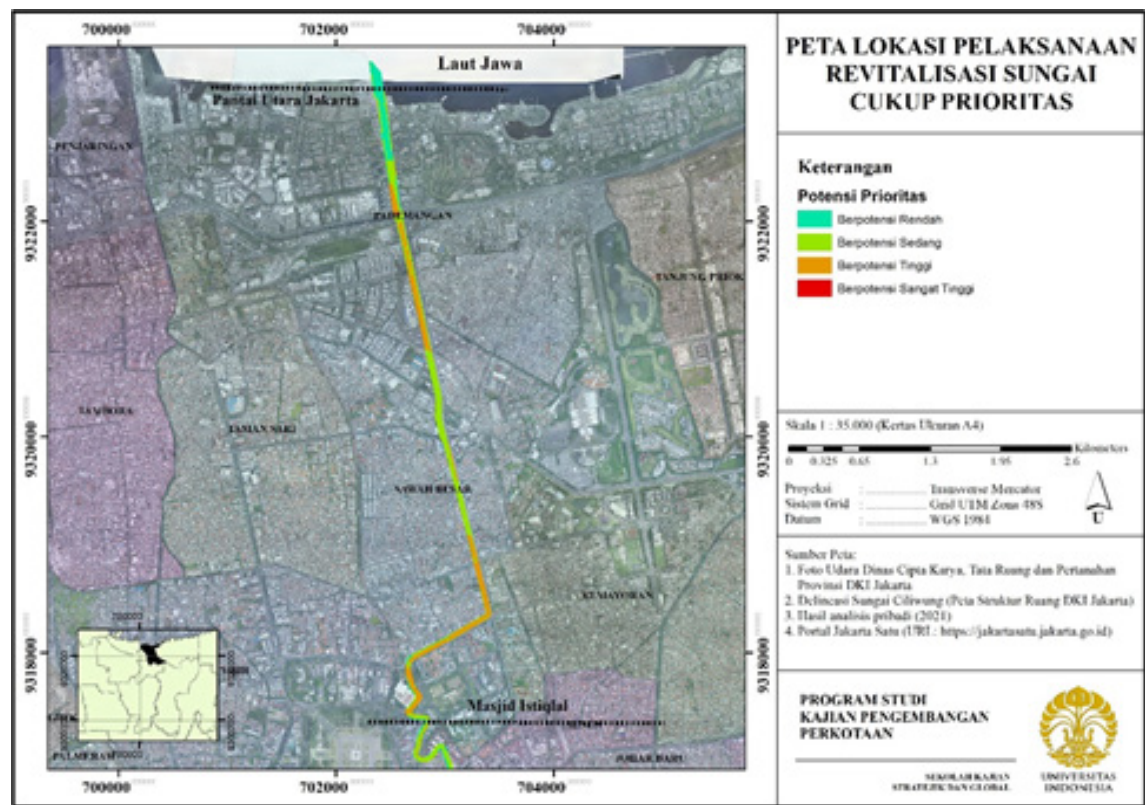

Gambar 4. Peta lokasi revitalisasi sungai ciliwung cukup prioritas: masjid istiqlal s.d pantai utara Jakarta.

.Figure 4. The map of the ciliwung river revitalization enough prioritized location:from the istiqlal mosque to Java's northern coast

Sumber: Hasil analisis data, 2021 


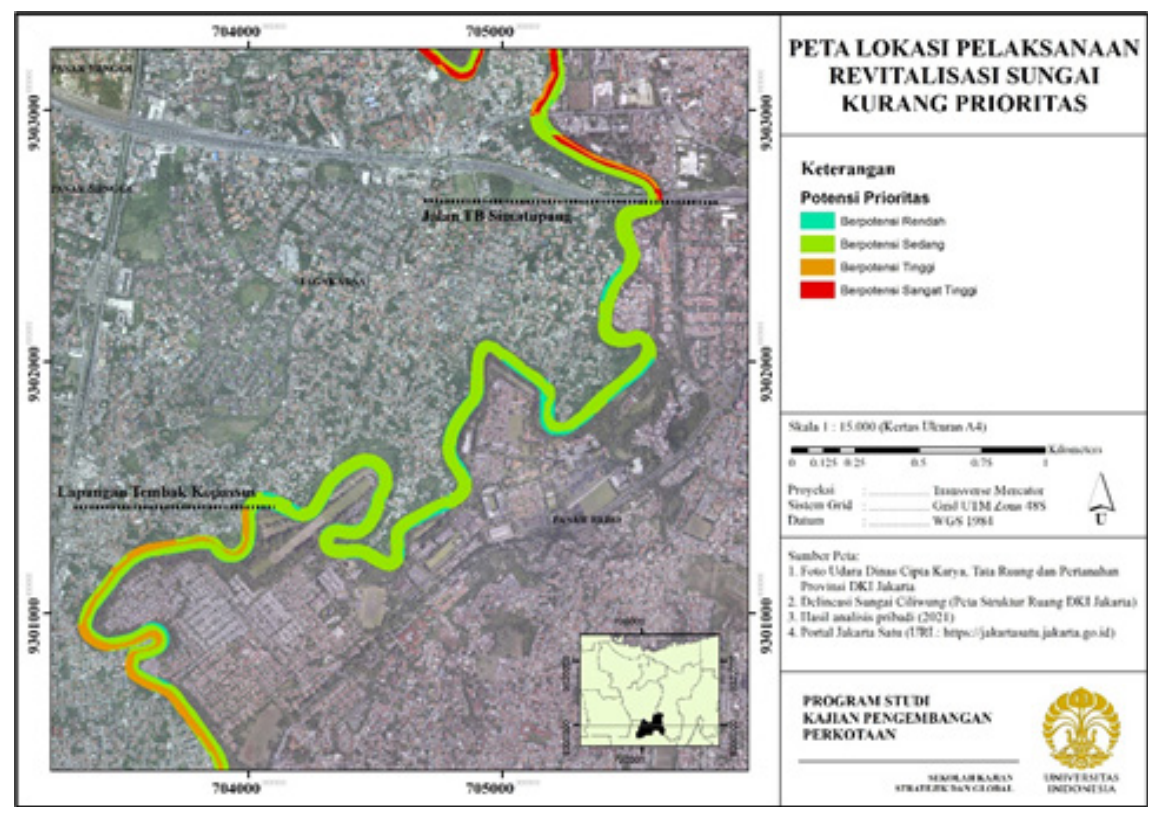

Gambar 5. Peta lokasi revitalisasi sungai ciliwung kurang prioritas:lapangan tembak kopassus s.d jalan TB simatupang. Figure 5. The map of the ciliwung river revitalization less prioritized location:from the kopassus shoot field to TB simatupang street.

Sumber: Hasil analisis data, 2021

berikut sempadannya pada segmen Lapangan Tembak Kopassus s.d Jalan TB Simatupang dan pada segmen Pintu Air Manggarai s.d Masjid Istiqlal didominasi oleh area berpotensi sedang, kemudian terdapat beberapa area yang tidak terlalu luas berpotensi rendah dan tinggi serta tidak terdapat area berpotensi sangat tinggi. Hal ini menyebabkan Sungai Ciliwung pada segmen

Lapangan Tembak Kopassus s.d Jalan TB Simatupang Lokasi revitalisasi Sungai Ciliwung tidak prioritas sebagaimana Gambar 5 dengan panjang $+4.261 \mathrm{~m}$ (lebih kurang empat ribu dua ratus enam puluh satu meter) dan segmen Pintu Air Manggarai s.d Masjid Istiqlal sebagaimana Gambar 6 dengan panjang +7.961 $\mathrm{m}$ (lebih kurang tujuh ribu Sembilan ratus enam puluh satu meter) menjadi lokasi revitalisasi kurang prioritas.

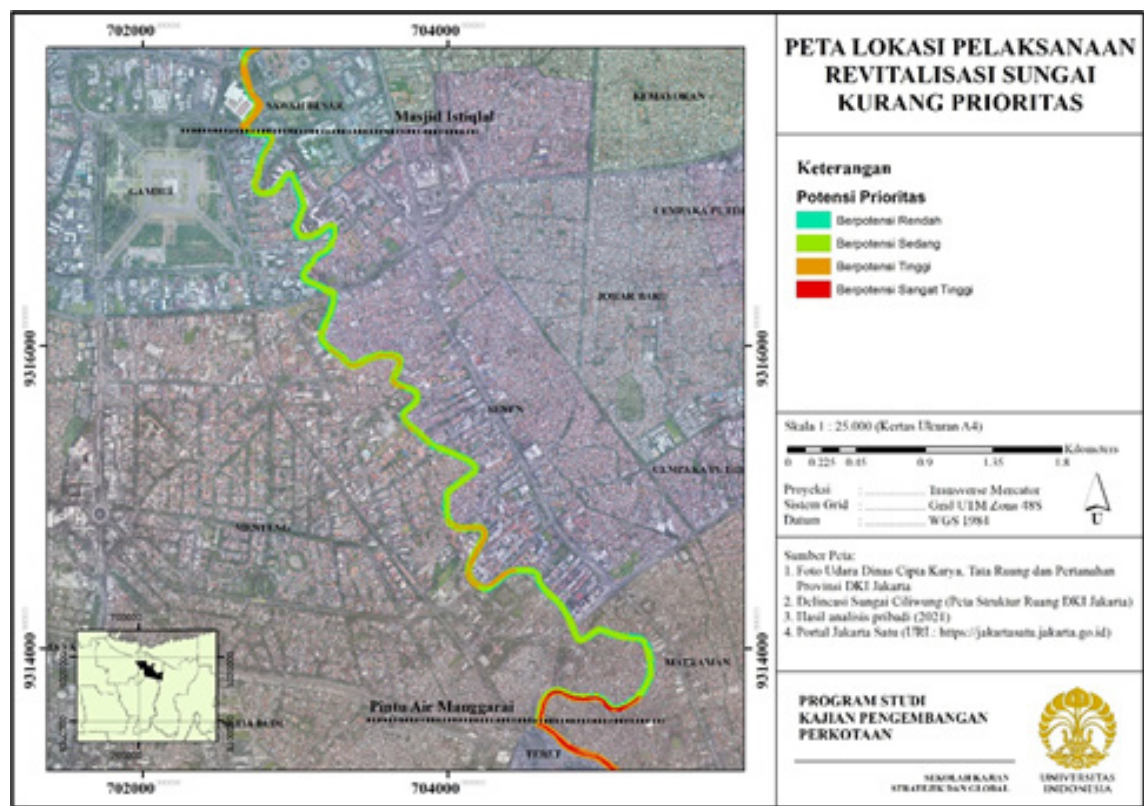

Gambar 6. Peta lokasi revitalisasi sungai ciliwung kurang prioritas:pintu air manggarai s.d masjid istiqlal.

Figure 6. The map of the ciliwung river revitalization less prioritized location:from manggarai water gate to the istiqlal mosque.

Sumber: Hasil analisis data, 2021 


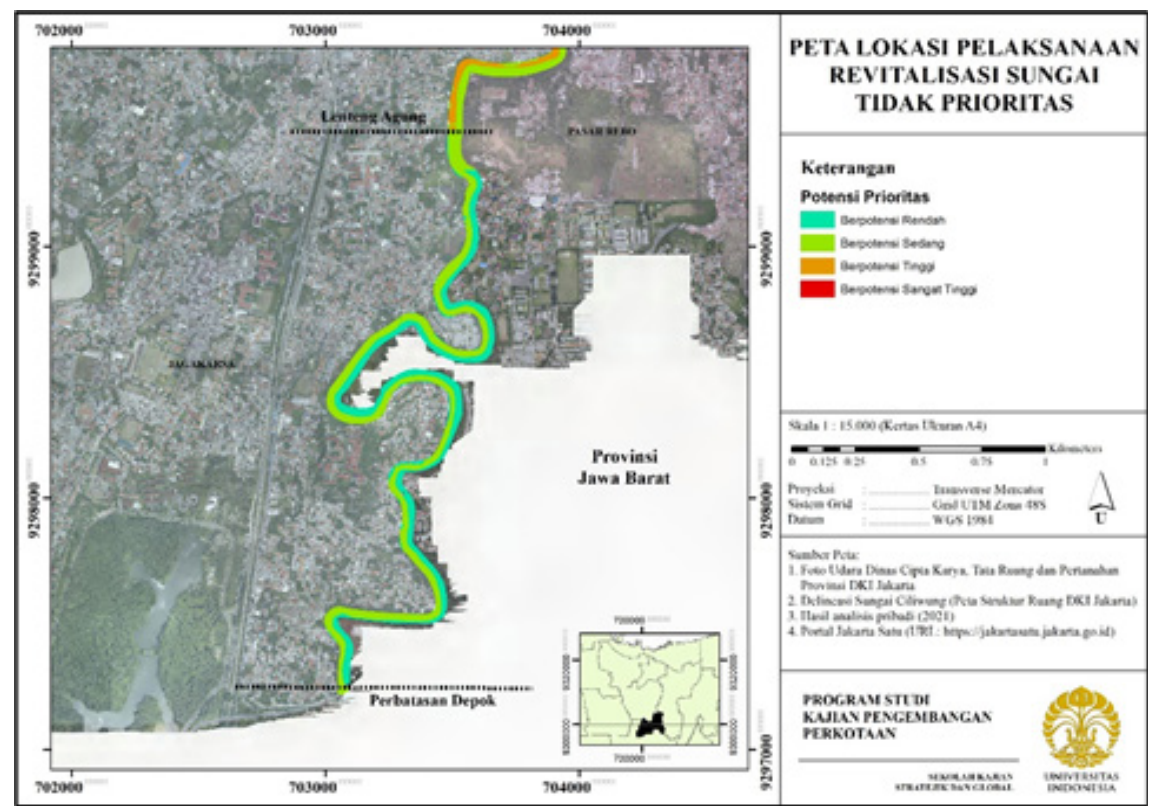

Gambar 7. Peta lokasi revitalisasi sungai ciliwung tidak prioritas.

.Figure 7. The map of the ciliwung river revitalization not prioritized location. Sumber: Hasil analisis data, 2021

sebagaimana Gambar 7 terletak mulai dari segmen Perbatasan Depok s.d Lenteng Agung. Area Sungai Ciliwung berikut sempadannya pada segmen ini didominasi oleh area berpotensi rendah dan sedang, serta tidak terdapat area berpotensi tinggi maupun area berpotensi sangat tinggi. Hal ini menyebabkan Sungai Ciliwung pada segmen Perbatasan Depok s.d Lenteng Agung dengan panjang $+4.300 \mathrm{~m}$ (lebih kurang empat ribu meter) ini menjadi lokasi revitalisasi tidak prioritas. Namun demikian revitalisasi Sungai Ciliwung pada segmen Perbatasan Depok s.d Lenteng Agung tetap perlu untuk dilaksanakan meskipun segmen ini menempati posisi prioritas terakhir setelah pelaksanaan revitalisasi Sungai Ciliwung pada segmen yang lain telah diselesaikan. Adapun kondisi Sungai Ciliwung pada segmen ini merupakan sungai dalam kawasan perkotaan yang tidak bertanggul.

\section{KESIMPULAN DAN SARAN}

Dalam menentukan lokasi revitalisasi sungai yang ideal terdapat beberapa kriteria yang perlu dipertimbangkan. Kriteria faktual banjir merupakan kriteria dengan bobot tertinggi, yaitu sebesar 32.4\% sehingga setiap segmen pelaksanaan revitalisasi sungai diharapkan dapat memiliki dampak yang besar sebagai pengendalian banjir di Jakarta. Kemudian bobot tertinggi kedua adalah kriteria simpangan penggunaan lahan sebesar $22,6 \%$, area terbangun pada kawasan revitalisasi ini perlu menjadi perhatian dalam kegiatan revitalisasi karena area yang sempadan sungai seharusnya dihijaukan sebagai penyangga sungai guna mempertahankan kelestarian fungsi sungai. Dan kriteria tertinggi ketiga adalah kriteria rencana kota dengan bobot $14.2 \%$, bahwa dukungan kebijakan Pemerintah diperlukan dalam kegiatan revitalisasi sungai dalam hal ini penegasan pada rencana tata ruang

Tabel 5. Prioritas lokasi revitalisasi sungai ciliwung

Table 5. Ciliwung river revitalization prioritised location

\begin{tabular}{|c|c|c|c|}
\hline No & Tingkat Prioritas & Segmen Sungai Ciliwung & $\begin{array}{l}\text { Panjang } \\
(+ \text { meter })\end{array}$ \\
\hline 1. & Sangat Prioritas & Jalan TB Simatupang s.d Pintu Air Manggarai & 23.993 \\
\hline \multirow[t]{2}{*}{2.} & Cukup Prioritas & Lenteng Agung s.d Lapangan Tembak Kopassus & 3.984 \\
\hline & & Masjid Istiqlal s.d Pantai Utara Jakarta & 6.635 \\
\hline \multirow[t]{2}{*}{3.} & Kurang Prioritas I & Lapangan Tembak Kopassus s.d Jalan TB Simatupang & 4.261 \\
\hline & & Pintu Air Manggarai s.d Masjid Istiqlal & 7.961 \\
\hline 4. & Tidak Prioritas & Perbatasan Depok s.d Lenteng Agung & 4.300 \\
\hline
\end{tabular}

JURNAL RISET JAKARTA, Vol. 14, No 2, NOVEMBER 2021, Hal. 65-76 
terhadap area revitalisasi.

Penilaian keseluruhan kriteria yang telah digabungkan dengan bantuan perangkat lunak ArcMap 10.4 diklasifikasian ke dalam 4 (empat) klasifikasi potensi yang dimiliki area tersebut untuk dilaksanakan revitalisasi Sungai Ciliwung sehingga didapatkan 4 (empat) tingkat prioritas lokasi revitalisasi Sungai Ciliwung sebagaimana dapat dilihat dalam Tabel 5.

Pemerintah disarankan agar dapat membuat satu komando terpusat pelaksanaan revitalisasi Sungai Ciliwung. Hal ini dikarenakan banyaknya peran yang terlibat dalam pelaksanaan penanganan sungai dengan kepentingan yang berbeda, ditambah dengan permasalahan sungai tidak dapat diselesaikan oleh satu wilayah Provinsi/Kota/Kabupaten karena Sungai Ciliwung mengalir dari hulu di Kawasan Gunung Gede, Kabupaten Bogor, mengalir melalui Kota Bogor, Kota Depok, sampai bermuara di wilayah Provinsi DKI Jakarta. Sehingga komando terpusat ini diperlukan agar keberjalanan program dapat selaras antar Pemerintah dan berkesinambungan dari hulu ke hilir. Kemudian dalam perencanaan dan pelaksanaan revitalisasi Sungai Cililiwung agar dapat mengajak akademisi dan masyarakat untuk bersama terlibat dalam rencana pengembangan kawasan sekitar Sungai Ciliwung.

Akademisi dapat melakukan pengabdian masyarakat dan mengembangkan riset terkait pelaksanaan revitalisasi sungai dengan mencontoh keberhasilan di Negara-negara luar yang menggunakan konsep revitalisasi dalam penanganan sungai dengan memerhatikan penerapannya di Indonesia, terutama pada Sungai Ciliwung. Saat ini, Pemerintah memiliki lembaga Badan Riset dan Inovasi Nasional (BRIN) yang bersamaan dengan hal tersebut juga tengah juga dibentuk pada level daerah yang disebut dengan Badan Riset dan Inovasi Daerah (BRIDA). Melalui BRIN dan BRIDA, akademisi dapat terus berkarya melahirkan riset dan inovasi terutama terkait revitalisasi sungai.

Masyarakat agar dapat terus menjaga semangat dalam berkomunitas untuk menjaga Sungai Ciliwung serta melakukan pengawalan terhadap kinerja Pemerintah dalam hal penanganan sungai, khususnya Sungai Ciliwung dengan memberikan saran dan kritik yang membangun melalui kanal-kanal resmi milik Pemerintah.

\section{UCAPAN TERIMA KASIH}

Ucapan terima kasih kami ucapkan kepada semua pihak yang telah membantu terlaksananya seluruh kegiatan penelitian sampai selesai.

\section{DAFTAR PUSTAKA}

Alokhina, T. (2020). Rivers revitalisation: Approaches to decision. E3S Web of Conferences, 166. https://doi. org/10.1051/e3sconf/202016601010

Arikunto, S. (2006). Prosedur Penelitian Suatu Pendekatan Praktik. Jakarta: Rineke Cipta.

Babbie, E. (2012). The Practice of Social Research 13th Edition. Medina: Wadsworth, Cangage Learning.

Bemmelen, V. (1949). The Geology of Indonesia Vol II. Netherlands: Netherlands Government Printing.

Bilby, R. E., \& Bisson, P. A. (1998). Function and Distribution of Large Woody Debris. In R. J. Naiman \& B. R.E. (Eds.), River Ecology and Management: Lessons From the Pacific Coastal Ecoregion (pp. 324-346). Springer-Verlag.

Bolton, S. M., \& Shellberg, J. (2001). Ecological Issues in Floodplains and Riparian Corridors. Final White Paper, July 2001, 88.

Budd, W. W., Cohen, P. L., Saunders, P. R., \& R., S. F. (1987). Stream Corridor Management in The Pacific Northwest: I. Determination of Stream-Corridor Widthstle. Environmental Management, 11, 587-597. https://doi.org/10.1007/BF01880157

Fisher, B., \& Turner, R. (2008): Ecosystem services: classification for valuation. In: Biological Conservation, 141(5), 1167-1169.

Hassan, R., Scholes, R., \& Ash, N. (2005). Ecosystems and human well-being. Current state and trends. Washington, DC: Island Press (Millennium ecosystem assessment series, 1).

Kementerian Pekerjaan Umum dan Perumahan Rakyat. (2015). Peraturan Menteri Pekerjaan Umum dan Perumahan Rakyat Republik Indonesia Nomor 28/ PRT/M/2015 tentang Penetapan Garis Sempadan Sungai dan Garis Sempadan Danau. Jakarta: Sekretariat Jenderal.

Pemerintah Provinsi DKI Jakarta. (1999). Peraturan Daerah Provinsi DKI Jakarta Nomor 6 Tahun 1999 tentang Rencana Tata Ruang Wilayah. Jakarta: Sekretariat Daerah. 
Pemerintah Provinsi DKI Jakarta. (1999). Peraturan Daerah Provinsi DKI Jakarta Nomor 9 Tahun 1999 tentang Pelestarian dan Pemanfaatan Lingkungan dan Bangunan Cagar Budaya. Jakarta: Sekretariat Daerah.

Pemerintah Provinsi DKI Jakarta. (2012). Peraturan Daerah Provinsi DKI Jakarta Nomor 7 Tahun 1999 tentang Prasarana, Sarana dan Utilitas Umum. Jakarta: Sekretariat Daerah.

Pemerintah Provinsi DKI Jakarta. (2014). Peraturan Daerah Provinsi DKI Jakarta Nomor 1 Tahun 2014 tentang Rencana Detail Tata Ruang dan Peraturan Zonasi. Jakarta: Sekretariat Daerah.

Pemerintah Provinsi DKI Jakarta. (2018). Peraturan Gubernur DKI Jakarta Nomor 90 Tahun 2018 tentang Peningkatan Kualitas Permukiman Dalam Rangka Penataan Kawasan Permukiman Terpadu. Jakarta: Sekretariat Daerah.

Pemerintah Provinsi DKI Jakarta. (2019). Peraturan Gubernur DKI Jakarta Nomor 31 Tahun 2019 tentang Pembangunan dan Revitalisasi Prasarana Sumber Daya Air Secara Terpadu Dengan Konsep Naturalisasi. Jakarta: Sekretariat Daerah.

Pemerintah Republik Indonesia. (2011). Peraturan Pemerintah Nomor 38 Tahun 2011 tentang Sungai. Jakarta: Kementerian Sekretariat Negara.

Saaty, T. L. (2001). Fundamentals of Decision Making and Priority Theory, Pittsburgh. Pennsylvania: RWS Publications.

Siswadhi. (1982). Intisari Edisi Maret 1982.

Team, R. P. (2012). Urban Rivers - Vital Spaces (E. Bender, L. Bigga, \& W. Maier (eds.)). Central Europe. 